\title{
Association of energy and protein intakes with length of stay, readmission and mortality in hospitalised patients with chronic obstructive pulmonary disease
}

\author{
Arora R. Ingadottir ${ }^{1,2 *}$, Anne M. Beck ${ }^{3,4}$, Christine Baldwin ${ }^{5}$, C. Elizabeth Weekes ${ }^{5}$, Olof G. Geirsdottir ${ }^{1,6}$, \\ Alfons Ramel ${ }^{1}$, Thorarinn Gislason ${ }^{7,8}$ and Ingibjorg Gunnarsdottir ${ }^{1,2}$ \\ ${ }^{1}$ Unit for Nutrition Research, Landspitali University Hospital E Faculty of Food Science and Nutrition, University of Iceland, \\ 101 Reykjavik, Iceland \\ ${ }^{2}$ Department of Clinical Nutrition, Landspitali University Hospital, 101 Reykjavik, Iceland \\ ${ }^{3}$ Department of Nutrition and Health, Faculty of Health and Technology, Metropolitan University College, Copenhagen N, \\ 2200 Copenhagen N, Denmark \\ ${ }^{4}$ Research Unit for Nutrition, Herlev and Gentofte Hospital, DK-2820 Gentofte, Denmark \\ ${ }^{5}$ Division of Diabetes and Nutritional Sciences, King's College London, London SE1 9NH, UK \\ ${ }^{6}$ The Icelandic Gerontological Research Institute, Landspitali University Hospital E University of Iceland, 101 Reykjavik, Iceland \\ ${ }^{7}$ Faculty of Medicine, University of Iceland, 101 Reykjavik, Iceland \\ ${ }^{8}$ Department of Respiratory Medicine and Sleep, Landspitali University Hospital, 108 Reykjavik, Iceland
}

(Submitted 9 October 2017 - Final revision received 29 November 2017 - Accepted 15 December 2017)

\section{Abstract}

Low energy and protein intakes have been associated with an increased risk of malnutrition in outpatients with chronic obstructive pulmonary disease (COPD). We aimed to assess the energy and protein intakes of hospitalised COPD patients according to nutritional risk status and requirements, and the relative contribution from meals, snacks, drinks and oral nutritional supplements (ONS), and to examine whether either energy or protein intake predicts outcomes. Subjects were COPD patients ( $n$ 99) admitted to Landspitali University Hospital in 1 year (March 2015-March 2016). Patients were screened for nutritional risk using a validated screening tool, and energy and protein intake for $3 \mathrm{~d}, 1-5 \mathrm{~d}$ after admission to the hospital, was estimated using a validated plate diagram sheet. The percentage of patients reaching energy and protein intake $\geq 75 \%$ of requirements was on average 59 and $37 \%$, respectively. Malnourished patients consumed less at mealtimes and more from ONS than lower-risk patients, resulting in no difference in total energy and protein intakes between groups. No clear associations between energy or protein intake and outcomes were found, although the association between energy intake, as percentage of requirement, and mortality at 12 months of follow-up was of borderline significance (OR $0 \cdot 12 ; 95 \%$ CI $0 \cdot 01,1 \cdot 15 ; P=0 \cdot 066$ ). Energy and protein intakes during hospitalisation in the study population failed to meet requirements. Further studies are needed on how to increase energy and protein intakes during hospitalisation and after discharge and to assess whether higher intake in relation to requirement of hospitalised COPD patients results in better outcomes.

Key words: Malnutrition: Chronic obstructive pulmonary disease: Mortality: Readmission: Length of stay

Malnutrition is a frequently observed problem in patients with chronic obstructive pulmonary disease (COPD) with an estimated prevalence of $20-45 \%$, depending on the criteria used to assess ${ }^{(1-4)}$. Malnutrition in patients with COPD is associated with higher mortality ${ }^{(5,6)}$, even after adjusting for possible confounders such as forced expiratory volume in $1 \mathrm{~s}$ $\left(\mathrm{FEV}_{1}\right)^{(6)}$ and length of hospital stay (LOS) is almost twice the duration in those who are malnourished compared to those who are at low nutritional risk ${ }^{(5)}$.

In general, low energy and protein intakes can be a cause of malnutrition in patients ${ }^{(7)}$, and decreased food intake among hospitalised patients has been observed in many studies in different patient groups ${ }^{(8-12)}$. Few studies have examined energy and protein intakes in hospitalised COPD patients ${ }^{(13-16)}$ and none have demonstrated whether there is a difference in intake associated with nutritional risk status or body composition. Vermeeren et $a l{ }^{(13)}$ reported an energy intake of 4469 (sD 2293) kJ (1068 (SD 548) kcal) at day 1 of hospitalisation, which increased substantially to 9050 (sD 2489) kJ (2163 (sD 595) kcal) at day 4 and remained stable until discharge in COPD patients hospitalised with an acute exacerbation (35\% had BMI $\leq 21 \mathrm{~kg} / \mathrm{m}^{2}$ ). A study by Sundwall et al. ${ }^{(14)}$ showed that despite enrichment of the hospital meals and use of oral nutritional supplements (ONS), which is recommended for patients at

Abbreviations: COPD, chronic obstructive pulmonary disease; FFMI, fat-free mass index; LOS, length of hospital stay; ONS, oral nutritional supplements; REE, resting energy expenditure.

* Corresponding author: A. R. Ingadottir, email aroraros@landspitali.is 
nutritional risk, the average energy intake on a group level during the whole hospital stay was lower than recommended in patients with severe COPD $\left(57 \%\right.$ had BMI $<22 \mathrm{~kg} / \mathrm{m}^{2}$ and $53 \%$ of the females and $76 \%$ of the males had low fat-free mass index (FFMI)). In a study by Vermeeren et $a l^{(15)}$, reduction in habitual intake before admission was reported by $51 \%$ of the nutritionally depleted hospitalised COPD patients, the majority of whom had severe or very severe disease (mean energy intake decreased from 9523 (sD 2636) to 6067 (sD 2247) kJ/d (2276 (sD 630) to 1450 (sD 537) $\mathrm{kcal} / \mathrm{d})$ ).

Although many hospitalised patients in different populations do not reach the recommended energy or protein intakes, it seems that achieving $\geq 75 \%$ of energy and protein requirements is critical ${ }^{(17)}$. A decreased risk of complications, shorter LOS and better body weight maintenance have been reported in general hospitalised patients at nutritional risk achieving $\geq 75 \%$ of their energy and protein requirements ${ }^{(12,17,18)}$, but studies that examine intake in both nutritionally adequate COPD patients and those at nutritional risk are lacking. Furthermore, information on the associations between dietary intake and diseaserelated variables other than malnutrition are rare in COPD patients. To our knowledge, only one study has previously examined the correlation between energy and protein intakes and disease severity in hospitalised patients with $\mathrm{COPD}^{(19)}$, and none has examined the association with prospective outcomes - for example LOS, readmission within $30 \mathrm{~d}$ or mortality. Low food and nutrient intake in general and in relation to requirement has been linked to increased mortality in a mixed group of hospitalised patients; however, only few of them had COPD $(5-7 \%)^{(8,9,12)}$. Thus, the aims of this study were: (1) to assess the overall energy and protein intakes of hospitalised patients with COPD according to nutritional risk status and requirements, and the relative contribution from meals, snacks, drinks and ONS; (2) to determine the number of patients achieving $\geq 75 \%$ of their predicted energy and protein requirements; and (3) to examine whether low energy and protein intakes in relation to requirements predicts LOS, hospital readmissions within $30 \mathrm{~d}$ and mortality in hospitalised patients with COPD.

\section{Methods}

\section{Subjects}

In this observational study, data were used in a cross-sectional and a longitudinal manner. Patients with COPD admitted to the Department of Pulmonary Medicine at the Landspitali National University Hospital were recruited from March 2015 until March 2016 ( $n$ 236) mostly owing to acute exacerbation. Patients able to eat and drink orally, who were judged to be able to maintain their balance on a device to measure body composition and who had an anticipated length of hospitalisation of $>3 \mathrm{~d}$ (evaluated by medical staff in the department) were invited to participate. Those who were not able to eat orally judged by Speech Pathologist and patients with cognitive impairment assessed with Mini-Mental Status Examination (MMSE) ${ }^{(20)}$ were excluded.

The study was approved by the hospital's Bioethics Committee (reference no. 12/2015) and by the medical directorate of the hospital (16, LSH 28-15). All patients provided written informed consent before their inclusion in the study. According to the hospital protocol, if patients were at nutritional risk according to screening (score $\geq 4$ ) (see below), individualised nutritional support was offered, for example, energy- and protein-dense food and/or ONS and/or dietary advice ${ }^{(21)}$. Standard food provision by the hospital kitchen to all patients consists of five meals daily, providing about $8368 \mathrm{~kJ}$ (2000 kcal) and $90 \mathrm{~g}(18 \% \mathrm{E})$ of protein daily. All types of additional food are allowed to be brought to the hospital by the patient and/or friends and relatives.

\section{Sample size considerations}

A priori sample size calculations indicated that a sample size of $36 /$ group would be sufficient to detect a difference of $837 \mathrm{~kJ}$ $(200 \mathrm{kcal})$ in energy intake as significant between wellnourished and malnourished patients assuming a sD of $1255 \mathrm{~kJ}$ (300 kcal) (with a given statistical power of $80 \%$ and a twosided significance level of $5 \%$ ). It has been shown that $837 \mathrm{~kJ}$ (200 kcal) is a clinically meaningful amount of energy that has been shown to improve anthropometric measures and grip strength in COPD patients ${ }^{(22)}$. Expecting a somewhat lower percentage of the participants to be malnourished than well nourished, the originally planned sample size was 100 .

A post hoc power analysis was performed with our total sample size of 99 and results from non-adjusted logistic regression analyses, achieving a power of $49 \%$ for LOS $\geq 7 \mathrm{~d}$, $70 \%$ for readmission within $30 \mathrm{~d}$ and $81 \%$ for mortality.

\section{Energy and protein intake}

Total energy and protein intakes from the five meals provided by the hospital kitchen were estimated using a validated plate diagram sheet ${ }^{(23,24)}$ for $3 \mathrm{~d}$ from 1 to $5 \mathrm{~d}$ after hospital admission, starting on the 1st day of participation in the study. After each meal, the proportion of the meal consumed by the subjects $(0$, 25,50 or $100 \%$ ) was recorded by a trained researcher or trained hospital staff ${ }^{(23,24)}$. The plate diagram sheet has special guidelines on how to record each meal (online Supplementary Appendix S1). Other snacks such as sweets, biscuits and yogurt and beverages such as coffee, soft drinks and milk consumed were also recorded, as well as intake from ONS. Total energy and protein intake per actual body weight per d was calculated.

Energy and protein content from hospital food and from food brought from home were analysed using Aivo2000 for Windows, version 1.12.0.1 (2012; AIVO, AB). Nutrition data in the programme is based on the Icelandic nutrient composition database (ISGEM). Nutritional content of ONS was obtained from the package label. To determine waste (in kJ (kcal) and g), the total amount eaten was deducted from the total amount provided to each patient.

\section{Energy and protein requirements}

Energy and protein requirements were estimated according to the lower limit recommended by the Icelandic clinical guidelines for hospitalised patients (energy $105 \mathrm{~kJ}$ ( $25 \mathrm{kcal}$ )/ kg per d and protein $1.2 \mathrm{~g} / \mathrm{kg}$ per $\mathrm{d})^{(21)}$. The equation is simple and 
frequently used in the clinical setting as it only requires body weight (not physical activity level or stress factor). It estimates total energy expenditure, which is close to the resting energy expenditure (REE) in hospitalised patients ${ }^{(21)}$. Adjustments were made before calculations if a patient's BMI was $<18.5 \mathrm{~kg} / \mathrm{m}^{2}$ (a factor for weight gain) and $>27 \mathrm{~kg} / \mathrm{m}^{2}-$ that is weight included that corresponds to a BMI of 18.5 and $27 \mathrm{~kg} / \mathrm{m}^{2}$ instead of actual weight.

\section{Nutritional risk screening}

For each patient, nutrition screening was undertaken by a trained researcher on admission. The screening tool used is recommended by the clinical guidelines for hospital nutrition at Landspitali ${ }^{(21)}$ and has been validated against a full nutritional assessment in COPD patients ${ }^{(3)}$ (online Supplementary Appendix S2) and predicts mortality in COPD patients ${ }^{(25)}$. Nutritional risk is categorised as low (score 0-1), medium (score 2-3) and high (score $\geq 4$ ). A total score of $\geq 4$ is considered 'at high nutritional risk'. Following screening, patients considered to be 'at nutritional risk' were categorised into those who were malnourished and those who were not malnourished using the criteria recently proposed by The European Society for Clinical Nutrition and Metabolism (ESPEN) ${ }^{(7)}$.

\section{Body composition}

Body composition was measured by a trained researcher in the morning, after breakfast within $48 \mathrm{~h}$ of study enrolment using a portable, multi-frequency $(20 \mathrm{kHz}, 100 \mathrm{kHz})$ bioelectrical impedance analysis (BIA) device (InBody230 Co., Ltd). The device measures a patient's weight $(\mathrm{kg})$, estimates total body water $(\mathrm{kg})$, body fat mass (BFM; $\mathrm{kg}$ ) and fat-free mass $(\mathrm{kg})$. BMI $\left(\mathrm{kg} / \mathrm{m}^{2}\right)$ and FFMI $\left(\mathrm{kg} \mathrm{FFM} / \mathrm{m}^{2}\right.$ ) were calculated. Information on height was collected from the electronic hospital patient records.

\section{Classification of disease severity}

$\mathrm{FEV}_{1}$ and forced vital capacity (FVC) were measured by spirometry (Jaeger MS-PFT ${ }^{\circledR}$; CareFusion) and disease severity was classified using the GOLD criteria ${ }^{(26)}$. All measurements were carried out by a trained researcher towards the end of the hospital stay.

\section{Electronic medical records}

Socio-demographic data, date of admission, readmission within $30 \mathrm{~d}$, LOS and mortality at 1 year of follow-up were collected from the electronic medical records from the hospital. LOS was both used as a continuous variable and dichotomous variable for example, $<7 \mathrm{~d}$ and $\geq 7 \mathrm{~d}-$ which is in agreement with policy at the hospital aiming that LOS should not exceed $7 \mathrm{~d}$.

\section{Statistical analysis}

Patients were stratified into four subgroups by nutritional status: (1) not at nutritional risk, (2) at nutritional risk by screening, (3) at nutritional risk by screening, but not malnourished and (4) malnourished according to ESPEN diagnosis. The
Kolmogorov-Smirnov test was used to test normality of data. Baseline characteristics were presented as medians and 95\% CI. Mann-Whitney $U$ test was used to test differences between continuous data and Pearson's $\chi^{2}$ test was used for categorical data. Logistic regression analyses were used to determine any associations between energy and/or protein intake, as a percentage of predicted requirements, and LOS $\geq 7 \mathrm{~d}, 30-\mathrm{d}$ readmission and mortality in a 12 -month follow-up. Results were shown in different models with various degrees of statistical correction: unadjusted (model 1), adjusted for nutritional status (model 2) and nutritional status and sex (model 3) because previous studies have shown association between those variables and outcomes measured ${ }^{(25,27,28)}$.

Statistical analysis was conducted using SPSS for Windows version 24.0 (SPSS) and the level of significance was set at $P<0.05$. G*Power Software for Windows version 3.1.9.2 (Heinrich-Heine-University Düsseldorf) was used to perform post hoc power analyses for logistic regression analyses.

\section{Results}

\section{Subjects}

In total, 236 patients were screened for nutritional risk during the study period. Of these, 29 (12\%) refused to participate and another $70(30 \%)$ patients were not eligible, because of a predicted admission of $<3 \mathrm{~d}(19(27 \%))$, not being able to stand in an upright position for $60 \mathrm{~s}$ (the time it takes to measure body composition using BIA) or judged by the nursing staff to be too sick to be able to participate (42 (60\%)). Of those, six were not able to eat orally, judged by a Speech Pathologist. Nine patients (13\%) were not eligible for other reasons - for example cognitive impairment (MMSE <19). Of those seventy patients who were not eligible, 25 (36\%) were defined as being at nutritional risk when using the screening tool proposed by Landspitali University hospital. A flow chart of recruitment is shown in Fig. 1.

In total, 137 (58\%) consented to participate in the study; however, 38 (28\%) had insufficient data available - e.g. early discharge and record of energy and protein intake discarded. Thus, ninety-nine participants were included in the present analyses (Table 1). All variables (except age, height and LOS) were significantly lower in malnourished patients (according to ESPEN criteria) compared with those who were not at nutritional risk by screening. Weight, BMI and BFM were also significantly lower in patients at nutritional risk by screening compared with those who were not at risk.

\section{Energy and protein intake}

At Landspitali, routine food provision by the hospital kitchen to all patients consists of five meals daily. Energy and protein intakes for each of the five meals and overall intake from all hospital food according to nutritional risk status are shown in Table 2. Median intake of energy and protein from both lunch and the evening meal and overall intake from hospital food was significantly lower in malnourished patients and those at nutritional risk than those who were not at risk $(P<0 \cdot 05)$. No significant difference was observed in energy and protein intakes 
from lunch and the evening meal, and overall intake from hospital food, between those at nutritional risk by screening but not malnourished and those who were not at risk. There were no differences between groups in energy and protein intakes at breakfast and afternoon and evening snack meals (Table 2).

The amount of food provided by the hospital kitchen did not vary between groups of patients (Table 3). However, significantly more food was wasted by patients who were at nutritional risk or malnourished compared with patients who were not at nutritional risk as they tended to consume less energy from the hospital food provided (Table 3).

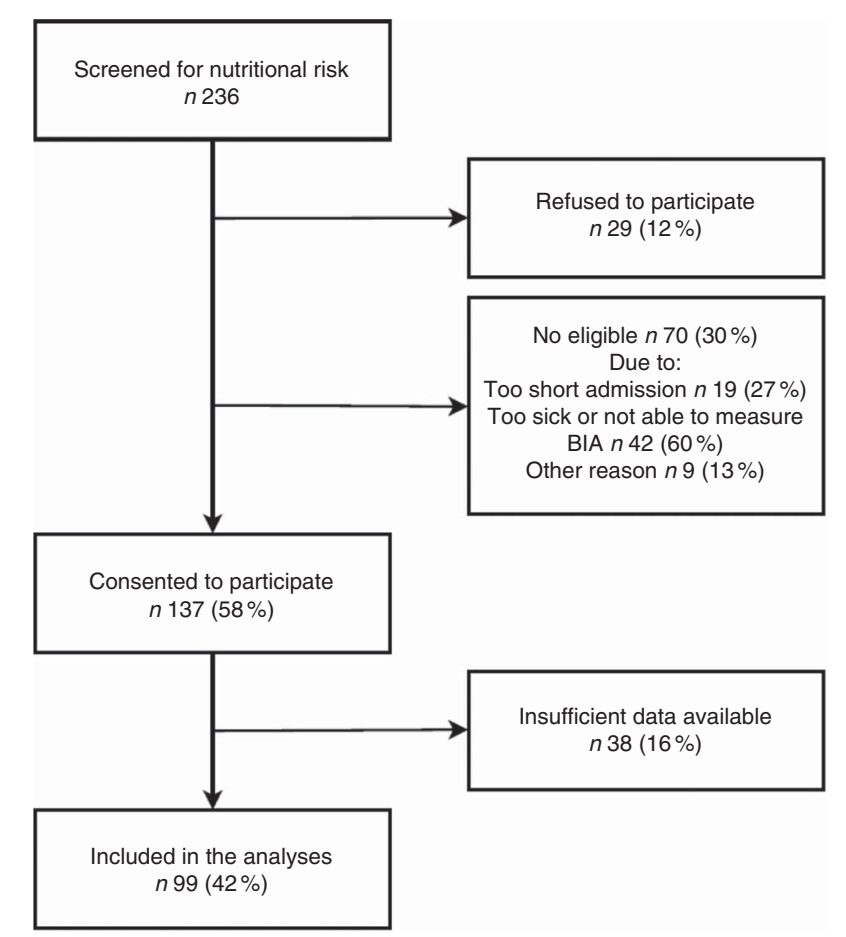

Fig. 1. Flow chart of recruitment. BIA, bioelectrical impedance analysis.
When intake from additional food brought to hospital by the patient and/or friends and relatives were considered with meals and snacks provided by the hospital, and intake from ONS, there was no significant difference between groups in overall daily energy and protein intakes. Patients at nutritional risk or malnourished consumed significantly more energy and protein from ONS than those who were not at nutritional risk. The quantity of additional food/snacks brought to hospital by the patient and/or friends and relatives was in general very low, with no difference in intake between groups (Table 3). According to our hospital protocol, appropriate dietary intervention is recommended to patients at nutritional risk, such as providing energy- and protein-dense hospital menu and ONS or in-between meals in addition to the hospital menu. Only fourteen (36\%) and twenty-two (56\%) of those patients received such intervention, respectively. However, total energy and protein intake significantly increased during hospitalisation among subjects at nutritional risk (from median 5314 (95\% CI 4059, 6372) kJ/d (1270 (95\% CI 970, 1523) kcal/d) at the 1 st day of food registration to 5858 (95\% CI 1117, 7167) kJ/d (1400 (95\% CI 267,1713$) \mathrm{kcal} / \mathrm{d}$ ) on the last day, $P=0 \cdot 008$, and $54.3 \mathrm{~g}$ of protein (95\% CI $0.9,65.6)$ to $59.4 \mathrm{~g}$ of protein (95\% CI 51.8, 71.3), $P=0.045$ ) (online Supplementary Table S5).

\section{Energy and protein requirements}

Overall, total energy and protein intakes for all groups failed to meet estimated requirements for energy and protein. Despite the lower predicted energy and protein requirements in patients diagnosed as malnourished using the ESPEN criteria, only $52 \%$ malnourished patients reached an energy intake above $75 \%$ of predicted requirements. The percentage of patients reaching $75 \%$ of their predicted protein needs was even lower than for energy, ranging from 31 to $44 \%$ in the four groups presented in Table 3. Energy requirements estimated using eight different equations/methods resulted in overall requirements varying from a median of 5264 (95\% CI 4971, 5356) to 8360 (95\% CI 8021 , 8799) kJ (1258 (95\% CI 1188, 1280) to 1998 (95\% CI 1917, 2103) kcal) in the whole group (online Supplementary Table S6).

Table 1. Patients' characteristics at baseline

(Medians and $95 \%$ confidence intervals; numbers and percentages)

\begin{tabular}{|c|c|c|c|c|c|c|c|c|c|c|}
\hline & \multicolumn{2}{|c|}{ All $(n 99)$} & \multicolumn{2}{|c|}{ Not at risk $(n 60)$} & \multicolumn{2}{|c|}{$\begin{array}{l}\text { Nutritional risk by } \\
\text { screening ( } n \text { 39) }\end{array}$} & \multicolumn{2}{|c|}{$\begin{array}{l}\text { Nutritional risk by } \\
\text { screening, but not } \\
\text { malnourished ( } n 16)\end{array}$} & \multicolumn{2}{|c|}{$\begin{array}{l}\text { Malnourished according } \\
\text { to ESPEN diagnosis } \\
(n 23)\end{array}$} \\
\hline & Median & $95 \% \mathrm{Cl}$ & Median & $95 \% \mathrm{Cl}$ & Median & $95 \% \mathrm{Cl}$ & Median & $95 \% \mathrm{Cl}$ & Median & $95 \% \mathrm{Cl}$ \\
\hline Age (years) & $73 \cdot 0$ & $71 \cdot 0,77 \cdot 0$ & $72 \cdot 0$ & $69 \cdot 0,74 \cdot 0$ & $79 \cdot 0^{*}$ & $71 \cdot 0,81 \cdot 0$ & $79 \cdot 5^{*}$ & $69 \cdot 0,86.0$ & $75 \cdot 0$ & $69.0,81.0$ \\
\hline \multicolumn{11}{|l|}{ Male/female } \\
\hline$n$ & \multicolumn{2}{|r|}{$45 / 54$} & \multicolumn{2}{|r|}{$27 / 33$} & \multicolumn{2}{|c|}{$18 / 21$} & \multicolumn{2}{|c|}{$7 / 9$} & \multicolumn{2}{|c|}{$11 / 12$} \\
\hline$\%$ & \multicolumn{2}{|r|}{$45 / 55$} & \multicolumn{2}{|r|}{$45 / 55$} & \multicolumn{2}{|c|}{$46 / 54$} & \multicolumn{2}{|c|}{$44 / 56$} & \multicolumn{2}{|c|}{$48 / 52$} \\
\hline Height (cm) & $169 \cdot 0$ & $167 \cdot 0,172 \cdot 0$ & $168 \cdot 5$ & $166 \cdot 0,174 \cdot 0$ & $170 \cdot 0$ & $163 \cdot 0,174 \cdot 0$ & 165.5 & $154 \cdot 0,180 \cdot 0$ & $172 \cdot 0$ & $163 \cdot 0,176 \cdot 0$ \\
\hline Weight (kg) & $68 \cdot 2$ & $64 \cdot 3,77 \cdot 1$ & $82 \cdot 1$ & $73 \cdot 0,88 \cdot 4$ & $54 \cdot 6^{*}$ & $49 \cdot 0,60 \cdot 5$ & $61 \cdot 3^{*}$ & $51 \cdot 0,83 \cdot 1$ & $51 \cdot 2^{*}$ & $45 \cdot 8,55 \cdot 8$ \\
\hline BMI $\left(\mathrm{kg} / \mathrm{m}^{2}\right)$ & $24 \cdot 8$ & $22 \cdot 7,26 \cdot 8$ & $28 \cdot 7$ & $26 \cdot 3,31 \cdot 3$ & $19 \cdot 1^{*}$ & $17 \cdot 5,20 \cdot 7$ & $22 \cdot 7^{*}$ & $19 \cdot 8,25 \cdot 8$ & $17 \cdot 4^{*}$ & $16 \cdot 3,18 \cdot 2$ \\
\hline Body fat mass $(\mathrm{kg})$ & $20 \cdot 6$ & $15 \cdot 5,24 \cdot 9$ & $29 \cdot 4$ & $24 \cdot 9,33 \cdot 6$ & $11 \cdot 4^{*}$ & $8 \cdot 0,14.6$ & $15 \cdot 7^{*}$ & $8 \cdot 0,21 \cdot 0$ & $9 \cdot 4^{*}$ & $6 \cdot 6,12 \cdot 3$ \\
\hline Fat-free mass $(\mathrm{kg})$ & $48 \cdot 9$ & $44 \cdot 3,52 \cdot 1$ & $52 \cdot 2$ & $45 \cdot 3,59 \cdot 0$ & $44 \cdot 0^{*}$ & $36 \cdot 8,49 \cdot 5$ & $49 \cdot 1$ & $34 \cdot 2,61 \cdot 5$ & $39 \cdot 8^{*}$ & $34 \cdot 4,47 \cdot 7$ \\
\hline Fat-free mass index $\left(\mathrm{kg} / \mathrm{m}^{2}\right)$ & $16 \cdot 9$ & $16 \cdot 1,17 \cdot 9$ & $18 \cdot 0$ & $17 \cdot 2,19 \cdot 5$ & $14 \cdot 8^{*}$ & $13 \cdot 8,16 \cdot 2$ & $17 \cdot 5$ & $14 \cdot 1,20 \cdot 3$ & $13 \cdot 9^{*}$ & $13 \cdot 1,15 \cdot 2$ \\
\hline FEV1 (\% predicted)† & $40 \cdot 0$ & $35 \cdot 0,50 \cdot 0$ & $45 \cdot 0$ & $35 \cdot 0,56 \cdot 0$ & $37 \cdot 0$ & $31 \cdot 0,47 \cdot 0$ & $47 \cdot 5$ & $31 \cdot 0,75 \cdot 0$ & $36 \cdot 0^{*}$ & $28 \cdot 0,41 \cdot 0$ \\
\hline Length of stay (d) & $9 \cdot 0$ & $9 \cdot 0,11 \cdot 0$ & $9 \cdot 0$ & $8 \cdot 0,11 \cdot 0$ & $10 \cdot 0$ & $9 \cdot 0,13 \cdot 0$ & $10 \cdot 5$ & $8 \cdot 0,18 \cdot 0$ & $10 \cdot 0$ & $9 \cdot 0,13 \cdot 0$ \\
\hline
\end{tabular}

ESPEN, European Society for Clinical Nutrition and Metabolism.

* Based on Mann-Whitney $U$ test. Significantly different from patients not at risk according to screening $(P<0.05)$.

† Not at risk: $n$ 52; nutritional risk by screening: $n$ 32; nutritional risk by screening, but not malnourished: $n 14$; malnourished according to ESPEN diagnosis: $n 18$. 
Table 2. Average energy and protein intake early in hospital stay in each meal in patients categorised by (1) nutritional risk by screening and (2) diagnosis of malnutrition using the European Society for Clinical Nutrition and Metabolism (ESPEN) criteria

(Medians and $95 \%$ confidence intervals)

\begin{tabular}{|c|c|c|c|c|c|c|c|c|}
\hline & \multicolumn{2}{|c|}{ Not at risk $(n 60)$} & \multicolumn{2}{|c|}{$\begin{array}{l}\text { Nutritional risk by } \\
\text { screening ( } n \text { 39) }\end{array}$} & \multicolumn{2}{|c|}{$\begin{array}{l}\text { Nutritional risk by screening, but } \\
\text { not malnourished }(n 16)\end{array}$} & \multicolumn{2}{|c|}{$\begin{array}{l}\text { Malnourished according to } \\
\text { ESPEN diagnosis }(n \text { 23) }\end{array}$} \\
\hline & Median & $95 \% \mathrm{Cl}$ & Median & $95 \% \mathrm{Cl}$ & Median & $95 \% \mathrm{Cl}$ & Median & $95 \% \mathrm{Cl}$ \\
\hline \multicolumn{9}{|l|}{ Energy $(\mathrm{kJ} / \mathrm{d})$} \\
\hline Breakfast & 1473 & 1326,1753 & 1544 & 1301,1753 & 1536 & 883,1753 & 1544 & 1314,1753 \\
\hline Lunch & 2134 & 1933,2343 & $1423^{*}$ & 1243,2013 & 1527 & 1159,2251 & $1356^{*}$ & 1238,2092 \\
\hline Afternoon snack & 837 & 724,874 & 728 & 577,874 & 728 & 452,874 & 732 & 498,933 \\
\hline Evening meal & 1904 & 1741,2054 & $1494^{\star}$ & 1113,1807 & 1648 & 1117,2130 & $1406^{*}$ & 916,1795 \\
\hline Evening snack & 602 & 523,632 & 561 & 397,577 & 561 & 372,682 & 548 & 205,690 \\
\hline Overall intake from hospital food $\dagger$ & 5803 & 4874,6523 & $4853^{*}$ & 3812,5418 & 5263 & 3799,5966 & $4105^{\star}$ & 3510,5481 \\
\hline \multicolumn{9}{|l|}{ Protein (g/d) } \\
\hline Breakfast & 9.7 & $8 \cdot 7,11.5$ & $9 \cdot 6$ & $7 \cdot 7,11 \cdot 1$ & 9.6 & $5.8,11.5$ & 9.6 & $7 \cdot 7,11.5$ \\
\hline Lunch & $25 \cdot 8$ & $20 \cdot 5,28 \cdot 6$ & $19 \cdot 1^{*}$ & $15 \cdot 2,24 \cdot 8$ & $21 \cdot 2$ & $13 \cdot 6,25 \cdot 6$ & $18 \cdot 1^{*}$ & $15 \cdot 0,24 \cdot 7$ \\
\hline Afternoon snack & 3.6 & $2.9,3.7$ & $3 \cdot 3$ & $2 \cdot 6,3 \cdot 7$ & $3 \cdot 2$ & $2.6,3.9$ & 3.3 & $2 \cdot 1,4 \cdot 0$ \\
\hline Evening meal & $21 \cdot 3$ & $19 \cdot 6,25 \cdot 8$ & $17 \cdot 3^{\star}$ & $12 \cdot 1,22 \cdot 6$ & $18 \cdot 8$ & $10 \cdot 4,26 \cdot 5$ & $17 \cdot 3^{*}$ & $11 \cdot 3,22 \cdot 6$ \\
\hline Evening snack & 4.3 & $3 \cdot 5,5 \cdot 8$ & $4 \cdot 2$ & $2 \cdot 9,5 \cdot 5$ & 4.6 & $2 \cdot 9,7.6$ & 4.2 & $0.8,5.8$ \\
\hline Overall intake from hospital food $†$ & $56 \cdot 2$ & $48 \cdot 6,58 \cdot 8$ & $45 \cdot 8^{*}$ & $38 \cdot 4,53 \cdot 8$ & $53 \cdot 8$ & $38 \cdot 4,67 \cdot 3$ & $40.9^{*}$ & $36 \cdot 0,52 \cdot 5$ \\
\hline
\end{tabular}

* Based on Mann-Whitney $U$ test. Significantly different from patients not at risk according to screening $(P<0.05)$.

$\dagger$ Median intake from overall intake from hospital food does not match with the sum calculation for each meal as some data for each meal are missing.

Table 3. Average energy and protein requirement, intake and plate waste in patients categorised by (1) nutritional risk by screening and (2) diagnosis of malnutrition using the European Society for Clinical Nutrition and Metabolism (ESPEN) criteria

(Medians and $95 \%$ confidence intervals)

\begin{tabular}{|c|c|c|c|c|c|c|c|c|}
\hline & \multicolumn{2}{|c|}{ Not at risk $(n 60)$} & \multicolumn{2}{|c|}{$\begin{array}{l}\text { Nutritional risk by } \\
\text { screening ( } n \text { 39) }\end{array}$} & \multicolumn{2}{|c|}{$\begin{array}{l}\text { Nutritional risk by screening, but } \\
\text { not malnourished }(n 16)\end{array}$} & \multicolumn{2}{|c|}{$\begin{array}{l}\text { Malnourished according to } \\
\text { ESPEN diagnosis }(n \text { 23) }\end{array}$} \\
\hline & Median & $95 \% \mathrm{Cl}$ & Median & $95 \% \mathrm{Cl}$ & Median & $95 \% \mathrm{Cl}$ & Median & $95 \% \mathrm{Cl}$ \\
\hline \multicolumn{9}{|l|}{ Energy $(\mathrm{kJ} / \mathrm{d})$} \\
\hline Meals served & 7878 & 7766,8008 & 7812 & 7498,7962 & 7845 & 7284,8104 & 7812 & 7456,7937 \\
\hline Meals eaten & 5803 & 4874,6523 & $4853^{\star}$ & 3812,5418 & 5263 & 3799,5966 & $4105^{\star}$ & 3510,5481 \\
\hline Waste & 1799 & 1280,2699 & $3088^{*}$ & 2063,3548 & 2121 & 1310,3515 & $3402^{*}$ & 2272,4071 \\
\hline \multicolumn{9}{|l|}{ From extra ONS/drinks/snacks } \\
\hline ONS & 0 & 0,0 & $431^{*}$ & 0,803 & $0^{*}$ & 0,891 & $577^{\star}$ & 176,837 \\
\hline Drinks & 176 & 71,347 & 71 & 21,293 & 46 & 13,276 & 163 & 21,364 \\
\hline Snacks & 0 & 0,0 & 0 & 0,0 & 0 & 0,0 & 0 & 0,121 \\
\hline Total intake & 6012 & 5117,6694 & 5782 & 4125,6268 & 5807 & 4117,6648 & 5234 & 4071,6268 \\
\hline Total intake $(\mathrm{kJ} / \mathrm{kg}$ per $\mathrm{d}) \dagger$ & 71 & 63,79 & $100^{*}$ & 79,117 & $92^{*}$ & 63,113 & $109^{*}$ & 79,142 \\
\hline Requirementł & 6870 & 6644,7134 & $5711^{*}$ & 5125,6330 & 6406 & 5335,6853 & $5356^{*}$ & 4791,5837 \\
\hline Intake/requirement§ & 377 & 310,397 & 347 & 272,406 & 331 & 259,406 & 356 & 268,460 \\
\hline \multicolumn{9}{|c|}{ Reaching $\geq 75 \%$ of requirementll } \\
\hline$n$ & \multirow{2}{*}{\multicolumn{2}{|c|}{$\begin{array}{l}38 \\
63\end{array}$}} & \multirow{2}{*}{\multicolumn{2}{|c|}{$\begin{array}{l}22 \\
56\end{array}$}} & \multirow{2}{*}{\multicolumn{2}{|c|}{$\begin{array}{l}10 \\
63\end{array}$}} & \multirow{2}{*}{\multicolumn{2}{|c|}{12}} \\
\hline$\%$ & & & & & & & & \\
\hline \multicolumn{9}{|l|}{ Protein $(\mathrm{g} / \mathrm{d})$} \\
\hline Meals served & $77 \cdot 3$ & $73 \cdot 6,79 \cdot 1$ & $77 \cdot 2$ & $74 \cdot 0,82 \cdot 2$ & 80.9 & $72 \cdot 6,83 \cdot 4$ & $75 \cdot 8$ & $71 \cdot 2,82 \cdot 2$ \\
\hline In meals served (\%E) & $16 \cdot 6$ & $16 \cdot 0,17 \cdot 5$ & $16 \cdot 5$ & $15 \cdot 7,17 \cdot 3$ & $17 \cdot 2$ & $15.4,19.4$ & 16.5 & $15 \cdot 1,17 \cdot 4$ \\
\hline Meals eaten & $56 \cdot 2$ & $48 \cdot 6,58 \cdot 8$ & $45 \cdot 8^{*}$ & $38.4,53.8$ & 53.8 & $38.4,67 \cdot 3$ & $40.9^{*}$ & $36 \cdot 0,52 \cdot 5$ \\
\hline From meals eaten (\%E) & $17 \cdot 1$ & $15 \cdot 8,17 \cdot 4$ & $16 \cdot 8$ & $15 \cdot 8,17 \cdot 5$ & $17 \cdot 1$ & $14.9,18 \cdot 1$ & $16 \cdot 6$ & $14 \cdot 7,17 \cdot 8$ \\
\hline \multirow{2}{*}{\multicolumn{9}{|c|}{$\begin{array}{l}\text { Waste } \\
\text { From extra ONS/drinks/snacks }\end{array}$}} \\
\hline & & & & & & & & \\
\hline ONS & 0.0 & $0.0,0.0$ & $4.0^{*}$ & $0.0,8 \cdot 0$ & $0.0^{*}$ & $0.0,10 \cdot 8$ & $6.0^{*}$ & $0.0,8.0$ \\
\hline Drinks & 1.4 & $0 \cdot 8,2 \cdot 2$ & 0.7 & $0.4,2 \cdot 0$ & 0.7 & $0.3,2.0$ & 0.7 & $0.4,3.6$ \\
\hline Snacks & 0.0 & $0.0,0.0$ & 0.0 & $0.0,0.0$ & 0.0 & $0.0,0.0$ & 0.0 & $0.0,0.3$ \\
\hline Total intake & 58.7 & $49 \cdot 7,62 \cdot 0$ & $54 \cdot 2$ & $41 \cdot 4,62 \cdot 8$ & 59.6 & $41 \cdot 4,67.5$ & 51.2 & $40 \cdot 7,59 \cdot 8$ \\
\hline Total intake $(\mathrm{g} / \mathrm{kg}$ per $\mathrm{d}) \dagger$ & 0.7 & $0 \cdot 6,0.8$ & $1.0^{*}$ & $0.7,1.2$ & 0.9 & $0.6,1.2$ & $1.0^{*}$ & $0.7,1 \cdot 3$ \\
\hline Requirement $\$$ & $88 \cdot 2$ & $82 \cdot 8,92 \cdot 5$ & $68.9^{*}$ & $62 \cdot 6,74.3$ & $73.5^{*}$ & $61 \cdot 2,91 \cdot 4$ & $65.5^{*}$ & $59.8,70 \cdot 3$ \\
\hline Intake/requirement§ & 63 & 60,74 & 69 & 58,81 & 67 & 54,90 & 69 & 53,84 \\
\hline \multicolumn{9}{|l|}{ Reaching $\geq 75 \%$ of requirementll } \\
\hline & \multirow{2}{*}{\multicolumn{2}{|c|}{$\begin{array}{l}21 \\
35\end{array}$}} & \multicolumn{2}{|r|}{15} & \multirow{2}{*}{\multicolumn{2}{|c|}{$\begin{array}{c}5 \\
31\end{array}$}} & \multirow{2}{*}{\multicolumn{2}{|c|}{$\begin{array}{l}10 \\
44\end{array}$}} \\
\hline$\%$ & & & & 39 & & & & \\
\hline
\end{tabular}

ONS, oral nutritional supplements.

* Based on Mann-Whitney $U$ test. Significantly different from patients not at risk according to screening $(P<0.05)$

† Values are based on intake per actual body weight.

‡ Calculations are based on lower value of estimated energy and protein requirement for other than intensive care unit patients (105 $\mathrm{kJ} / \mathrm{kg} \mathrm{per} \mathrm{d})$ and $(1.2 \mathrm{~g} / \mathrm{kg}$ per $\mathrm{d})$ recommended by Icelandic clinical guidelines ${ }^{(21)}$. Adjustments were made before calculations if a patients' BMI was $<18.5$ and $>27 \mathrm{~kg} / \mathrm{m}^{2}$.

$\S$ Intake from the five meals served from the hospital kitchen (Extra ONS/drinks/snacks not included) as percentage of requirement.

II Number of patients reaching $\geq 75 \%$ of requirement from the five meals served from the hospital kitchen (extra ONS/drinks/snacks not included). 


\section{Energy and protein intake health-related outcomes}

Adjusted and non-adjusted logistic regression models were used to investigate whether energy and/or protein intakes in relation to requirement early in hospital stay were predictors of adverse health outcomes. In total, seventy-five (76\%) patients had LOS $\geq 7 \mathrm{~d}$, twenty-one ( $21 \%$ ) were re-admitted within $30 \mathrm{~d}$ and twenty-two (22\%) died within 12 months.

Associations between energy and protein intakes in relation to requirement and outcomes in our study were not statistically significant (Table 4). However, there was a trend towards a lower risk of 12-month mortality with higher energy intake in relation to requirements (OR 0.12; $95 \%$ CI 0.01, 1.15; $P=0.066$ ).

We observed similar results when we assessed whether energy and protein intakes below $75 \%$ of energy and protein requirements were predictors of adverse health outcomes.

FFMI was higher in patients with a higher intake of both energy and protein. FFMI increased by $1.5 \mathrm{~kg} / \mathrm{m}^{2}$ for every additional $2092 \mathrm{~kJ}(500 \mathrm{kcal})$ and $1.2 \mathrm{~kg} / \mathrm{m}^{2}$ for every additional $20-\mathrm{g}$ intake of protein. Similar association was also seen for BMI $\left(y=2.5 \mathrm{~kg} / \mathrm{m}^{2}\right.$ per $2092 \mathrm{~kJ}$ (500 kcal), $P=0.009$ and $y=2.26 \mathrm{~kg} / \mathrm{m}^{2}$ per $20 \mathrm{~g}, P=0.005)$. No associations were seen between energy and protein intakes and lung function $\left(y=3.5 \mathrm{~kg} / \mathrm{m}^{2}\right.$ per $2092 \mathrm{~kJ}$ (500 kcal), $P=0.273$ and $y=2.3 \mathrm{~kg} / \mathrm{m}^{2}$ per $20 \mathrm{~g}, P=0.426$ ).

\section{Discussion}

Overall energy and protein intake from the five meals provided by the hospital kitchen was significantly lower in patients at high nutritional risk or malnourished than patients who were not at risk. However, total daily intake of energy and protein, including snacks and ONS, was similar across all groups, although all groups failed to meet their estimated requirements for energy and protein. Patients at nutritional risk and those who were malnourished consumed significantly less energy and protein from the two main meals provided, lunch and dinner, despite being served similar amounts, but there was no difference in intake between groups from breakfast and the smaller 'in-between meals' (afternoon and evening snacks).
Our results suggest that malnourished patients have difficulty in consuming large meals (lunch/dinner) but the additional consumption of smaller energy-dense meals in similar amounts to normally nourished patients is feasible. It has been shown that smaller, energy-dense meals can increase energy and protein intakes of hospitalised patients ${ }^{(29)}$, and a more even distribution of food provided throughout the day might lead to a higher total energy intake in this group. Furthermore, as REE is often elevated in weight-losing patients with $\operatorname{COPD}^{(29,30)}$, providing them with extra energy-dense meals might be beneficial as it could prevent further weight loss and promote weight gain, which can reduce the risk of mortality ${ }^{(31)}$.

It appears that, in the short term, patients at nutritional risk or malnourished rely more on ONS than food to improve their intakes than do normally nourished patients. It is not known, however, whether this group of patients would maintain this approach in the longer term or indeed whether it relates to the practicalities of obtaining food during a hospital admission. In the early phase of a COPD exacerbation, ONS might be more effective at improving energy and protein intake, as liquids are easier to consume and require less chewing in the presence of nutrition impact symptoms such as shortness of breath and early satiety, which increase the work of eating. There is a need for studies looking at food fortification of texture modified meals in COPD patients that require less time and effort to consume. In a systematic review by Hubbard et al. ${ }^{(32)}$ in general adult patients, no significant differences in compliance with ONS consumption were found between different settings - i.e. hospital and community. However, there is considerably less information on the compliance with in-between meal snacks and food fortification, both in hospital and after discharge. According to our hospital protocol, appropriate dietary intervention is recommended to patients at nutritional risk such as providing energy- and protein-dense hospital menu and ONS or in-between meals in addition to the hospital menu. However, only fourteen (36\%) and twenty-two (56\%) of those patients in our study received such intervention, respectively.

The energy intake of subjects in our study is considerably lower than seen in many other studies in patients with

Table 4. Association between overall energy and protein intake from hospital food as a percentage of predicted requirements, and length of hospital stay $(\geq 7 \mathrm{~d})$, readmission within $30 \mathrm{~d}$ and mortality within 12 months $(n 99)$ (Odds ratios and $95 \%$ confidence intervals)

\begin{tabular}{|c|c|c|c|c|c|c|c|c|c|c|c|c|}
\hline & \multicolumn{4}{|c|}{ Model $1^{*}$} & \multicolumn{4}{|c|}{ Model $2 \dagger$} & \multicolumn{4}{|c|}{ Model $3 \ddagger$} \\
\hline & OR & $95 \%$ & $\mathrm{Cl}$ & $P$ & OR & $95 \%$ & $\mathrm{Cl}$ & $P$ & OR & $95 \%$ & $\mathrm{Cl}$ & $P$ \\
\hline \multicolumn{13}{|l|}{ Length of stay $\geq 7 d$} \\
\hline Energy intake/requirement§ & 0.49 & 0.07 & 3.53 & 0.477 & 0.46 & 0.06 & 3.44 & 0.451 & 0.45 & 0.06 & $3 \cdot 37$ & 0.438 \\
\hline Protein intake/requirement§ & 0.27 & 0.03 & $2 \cdot 63$ & 0.261 & 0.22 & 0.02 & $2 \cdot 23$ & 0.199 & 0.17 & 0.02 & 1.94 & 0.154 \\
\hline \multicolumn{13}{|l|}{ Readmission within $30 \mathrm{~d}$} \\
\hline Energy intake/requirement§ & 0.22 & 0.03 & 1.96 & 0.175 & 0.22 & 0.03 & 1.97 & 0.176 & 0.22 & 0.03 & 1.99 & 0.178 \\
\hline Protein intake/requirement§ & 0.48 & 0.04 & 5.43 & 0.554 & 0.49 & 0.04 & 5.56 & 0.561 & 0.50 & 0.04 & 5.72 & 0.573 \\
\hline \multicolumn{13}{|l|}{ Mortality within 12 months } \\
\hline Energy intake/requirement§ & 0.15 & 0.02 & 1.33 & 0.088 & 0.13 & 0.01 & 1.22 & 0.074 & 0.12 & 0.01 & $1 \cdot 15$ & 0.066 \\
\hline Protein intake/requirement§ & 0.29 & 0.03 & 3.28 & 0.317 & 0.20 & 0.02 & 2.42 & 0.205 & 0.17 & 0.01 & $2 \cdot 12$ & 0.168 \\
\hline
\end{tabular}


$\mathrm{COPD}^{(33-36)}$. However, in most of these studies, subjects were stable outpatients. Most of our subjects were hospitalised owing to an acute exacerbation, and this may have interfered with their ability or desire to eat. In some patients, inflammation is associated with an increase in $\mathrm{REE}^{(37)}$, which, in the presence of poor dietary intake, may contribute to impaired energy balance $^{(13)}$. Many studies now show, however, that although acutely unwell patients have an increase in REE this is more than compensated for by a decrease in physical activity. As a result, total daily energy expenditure is unlikely to be more in sick patients than in healthy individuals ${ }^{(38,39)}$. In a study by Vermeeren et al. ${ }^{(13)}$, energy intake was 4469 (sD 2293) kJ (1068 (sD 548) kcal) on the 1st day during hospitalisation but increased substantially to 9050 (sD 2489) kJ (2163 (sD 595) kcal) at day 4. Although a higher energy intake was seen in a previous study in Iceland $(7615 \mathrm{~kJ} / \mathrm{d}(1820 \mathrm{kcal} / \mathrm{d}))^{(16)}$, the median total energy intake for the $3 \mathrm{~d}$ measured in all subjects in our study was 5778 (sD 1598) kJ (1381 (sD 382) kcal). However, in agreement with the study by Vermeeren et $a l^{(13)}$, total energy and protein intakes in our study significantly increased during hospitalisation among subjects at nutritional risk (from median 5314 (95\% CI 4059,6372$) \mathrm{kJ} / \mathrm{d}(1270(95 \%$ CI 970,1523$) \mathrm{kcal} / \mathrm{d})$ to 5858 (95\% CI 1117, 7167) kJ/d (1400 (95\% CI 267, 1713) kcal/d) and $54 \cdot 3(95 \%$ CI $0.9,65.6) \mathrm{g}$ protein/d to $59 \cdot 4$ (95\% CI 51.8, 71.3) g protein/d). The reason for different results might be related to differences in methodology - for example, the duration and timing of the dietary record ${ }^{(13)}$ or dietary assessment method $^{(23)}$. Furthermore, an increased intake during hospitalisation might be expected owing to resolution of the disease exacerbation and nutrition impact symptoms such as dyspnoea facilitating improved eating and loss of appetite ${ }^{(15)}$.

In our study, the proportion of patients with intake above $75 \%$ of their predicted energy and protein requirements did not differ according to nutritional status. We used the lower limits (energy $105 \mathrm{~kJ} / \mathrm{kg}$ per $\mathrm{d}$ and protein $1.2 \mathrm{~g} / \mathrm{kg}$ per $\mathrm{d}$ ) recommended by Icelandic clinical guidelines ${ }^{(21)}$, but the number of patients reaching $75 \%$ of their energy requirements differed when using different equations to estimate energy requirement. Two equations have been developed to predict REE in COPD patients. In 1988, Moore \& Angelillo developed a diseasespecific formula mainly in men with COPD $^{(40)}$, and in 2010 Nordenson et al. developed a disease-specific formula in underweight patients with $\operatorname{COPD}^{(41)}$. Using those equations would have resulted in a different number of patients reaching the suggested cutoff ( $\geq 75 \%$ ). However, the evidence base for this cutoff is weak and, to our knowledge, has only been assessed in a mixed group of hospitalised patients ${ }^{(12,17,18)}$.

There are also some limitations when estimating energy requirements with the above-mentioned equations - for example, the equation used in our study and the equation by Moore \& Angelillo $^{(40)}$ only contains body weight. Considering FFM is a major factor predicting REE in COPD patients ${ }^{(30,42,43)}$, the prediction of energy requirements using body weight alone may be inaccurate. In the equation by Nordenson et al. ${ }^{(41)}$, FFM was used to determine energy requirements; however, their equation was derived from malnourished but weight-stable COPD patients and may not therefore be applicable to other COPD populations - for example weight-losing malnourished patients or weight-stable adequately nourished patients. Weight loss is prevalent in patients with COPD and those patients have higher measured REE compared with those who are weight stable ${ }^{(30)}$, and thus all those equations might underestimate REE.

There was a tendency towards a lower risk of mortality in those patients who met a higher proportion of their energy requirements; however, the association did not reach statistical significance. Decreased energy intake is associated with increased mortality in elderly hospitalised patients, although few of them had COPD $(7 \%)^{(9)}$. Furthermore, food intake was assessed in 16290 adult hospitalised patients (5.7\% with COPD) on Nutrition Day 2006. Consuming a quarter of the food provided on Nutrition Day was associated with an increased risk for dying, with an adjusted hazard ratio of $2 \cdot 10$ (95\% CI $1.53,2.89$ ); when eating nothing 3.02 (95\% CI $2.11,4.32$ ) compared with those who consumed all the portion ${ }^{(8)}$. The prevalence of mortality was similar in the present study as in other studies $^{(5,44)}$. We did not find associations with energy and protein intake and other end points. The lack of significant associations between intake and outcomes in our study might be related to the very low energy and protein intakes observed, with thirty-nine (39\%) and sixty-three (64\%) not achieving $\geq 75 \%$ of energy and protein requirement. Higher intakes may be required to achieve a beneficial effect on LOS and readmission rate. In this study, a higher proportion of patients was re-admitted within $30 \mathrm{~d}(21 \%)$ than has been shown in other studies $^{(45,46)}$, and it may be that low energy and protein intakes contributed to the high readmission rate, especially if intakes did not increase considerably after discharge ${ }^{(12)}$. However, the lack of associations could also be due to the short period of time - that is intake only measured for $3 \mathrm{~d}$ early in hospital stay. It has been shown that nutritional supplementation (mainly using ONS) in COPD outpatients can have a positive impact on total dietary intake, body weight gain, functional capacity and quality of life ${ }^{(22,47-49)}$. The timing and type of nutritional intervention during hospitalisation also needs to be studied further and outcomes relevant to hospital management (e.g. LOS and readmissions within $30 \mathrm{~d}$ ) should be included in future studies. For example, nutritional intervention offered to those at medium nutritional risk before functional decline rather than only those at high risk and ONS and/or snacks offered rather than emphasising large meals such as lunch and dinner. Prioritising patients not reaching their requirement and those who would benefit from nutritional support might be an appropriate priority for the dietetic services.

Higher energy and protein intakes were related to higher BMI and FFMI of our study participants. This is of importance as a higher BMI and a higher FFMI are related to better survival and more favourable health outcomes in COPD patients ${ }^{(31,43,50,51)}$. In a study by Yilmaz et al. ${ }^{(36)}$, similar energy and protein intakes was observed in patients with low and normal FFMI (7406

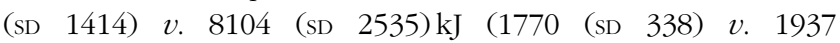
(sD 606) kcal), $P=0.478$ and 68.4 (sD 15.4) $v .73 .7$ (sD 26.7) g, $P=0.946)^{(36)}$. In contrast, a study by Van de Bool et al. ${ }^{(34)}$ showed that COPD patients with low FFMI had a higher energy intake than patients with normal FFMI (9084 (95\% CI $7385,11494) v .8297$ (95 \% CI 6820, 10176) $\mathrm{kJ} ; P=0.001)$ and 
the protein intake per $\mathrm{kg}$ body weight was higher in subjects with low FFMI (1.0 g; $95 \%$ CI 0.8, $1.3 v .1 .3 \mathrm{~g}$; $95 \%$ CI 1.0, 1.8, $P<0.001)$. However, higher energy and protein intake in subjects with low FFMI should not be surprising owing to the risk for increased energy expenditure, and as this group might be considered at nutritional risk, they are more likely to receive nutritional therapy in the form of dietary advice and/or ONS ${ }^{(42)}$.

To our knowledge, only one study has previously examined the correlation between energy and protein intake and disease severity in patients with COPD ${ }^{(19)}$. Our findings agree with the previous study results that showed no correlation between energy intake and disease severity. However, in their study a weak correlation was seen between protein intake assessed with FFQ and certain variables related to lung function (FVC and $\mathrm{VC}$ ). No relation was seen with other variables measured $\left(\mathrm{FEV}_{1} \text { and } \mathrm{FEV}_{1} / \mathrm{FVC}\right)^{(19)}$.

It is a limitation of the present study that it was of observational design and although we almost reached our calculated sample of 100, a relatively small sample was in each nutritional risk subgroup. We recognise that measuring intake for only $3 \mathrm{~d}$ early in hospital stay and not the whole period of hospitalisation could be a limitation as it is therefore not possible to assess resolution of intake at hospital discharge. Unfortunately, we did not assess habitual intake when well, only in the acute state of hospitalisation. The power calculations were based on difference in energy intake between groups, but we might have been underpowered to see significant associations with outcomes. However, this study provides important information about dietary intake early in hospital stay in inpatients with COPD, which might be used both to guide clinical work and future research.

\section{Conclusions}

Energy and protein intake during hospitalisation failed to meet estimated energy and protein requirements. Despite receiving similar amounts of food from the hospital, energy and protein intakes from the two meals (lunch and evening meal) were lower in malnourished patients than in those who were not at nutritional risk. However, the contribution of ONS was higher among malnourished patients, resulting in no difference in daily total energy and protein intakes between the groups. Hospitalisation should be considered a window of opportunity for detailed nutritional assessment and implementation of longterm nutritional therapy ${ }^{(52)}$. Further studies are needed on how to increase energy and protein intake during hospitalisation and after discharge, and to assess whether higher intakes in relation to requirements of COPD patients results in better outcomes.

\section{Acknowledgements}

The authors acknowledge the staff at the Thoracic ward and the Thoracic outpatient's clinic at Landspitali National University Hospital, Reykjavik, Iceland, and Eva Bjorg Bjorgvinsdottir for their contribution to the data collection.

This study was funded by the Icelandic Research Fund of the Icelandic Centre for Research (141216-051), the University of Iceland Research Fund and the Landspitali University Hospital Research Fund.
Concept and design of study and finalising manuscript and analysis and interpretation of data: A. R. I., I. G., A. M. B., C. B., C. E. W., A. R., T. G. and O. G. G. Data collection and data management and writing the manuscript: A. R. I. All authors participated in editing and final revisions of the manuscript. All authors have read and approved the final manuscript.

The authors declare that there are no conflicts of interest.

\section{Supplementary material}

For supplementary material/s referred to in this article, please visit https://doi.org/10.1017/S0007114517003919

\section{References}

1. Collins PF, Elia M, Kurukulaaratchy RJ, et al. (2016) The influence of deprivation on malnutrition risk in outpatients with chronic obstructive pulmonary disease (COPD). Clin Nutr (epublication ahead of print 11 November 2016).

2. Vermeeren MA, Creutzberg EC, Schols AM, et al. (2006) Prevalence of nutritional depletion in a large out-patient population of patients with COPD. Respir Med 100, 1349-1355.

3. Thorsdottir I, Gunnarsdottir I \& Eriksen B (2001) Screening method evaluated by nutritional status measurements can be used to detect malnourishment in chronic obstructive pulmonary disease. J Am Diet Assoc 101, 648-654.

4. Hogan D, Lan LT, Diep DT, et al. (2016) Nutritional status of Vietnamese outpatients with chronic obstructive pulmonary disease. J Hum Nutr Diet 30, 83-89.

5. Hoong JM, Ferguson M, Hukins C, et al. (2016) Economic and operational burden associated with malnutrition in chronic obstructive pulmonary disease. Clin Nutr 36, 1105-1109.

6. Hallin R, Gudmundsson G, Suppli Ulrik C, et al. (2007) Nutritional status and long-term mortality in hospitalised patients with chronic obstructive pulmonary disease (COPD). Respir Med 101, 1954-1960.

7. Cederholm T, Bosaeus I, Barazzoni R, et al. (2015) Diagnostic criteria for malnutrition - an ESPEN Consensus Statement. Clin Nutr 34, 335-340.

8. Hiesmayr M, Schindler K, Pernicka E, et al. (2009) Decreased food intake is a risk factor for mortality in hospitalised patients: the NutritionDay survey 2006. Clin Nutr 28, 484-491.

9. Sullivan DH, Sun S \& Walls RC (1999) Protein-energy undernutrition among elderly hospitalized patients: a prospective study. JAMA 281, 2013-2019.

10. Thibault R, Chikhi M, Clerc A, et al. (2011) Assessment of food intake in hospitalised patients: a 10-year comparative study of a prospective hospital survey. Clin Nutr 30, 289-296.

11. Ingadottir AR, Hilmisdottir HB, Ramel A, et al. (2015) Energyand protein intake of surgical patients after the implementation of energy dense hospital menus. Clin Nutr ESPEN 10, e107-e111.

12. Agarwal E, Ferguson M, Banks M, et al. (2013) Malnutrition and poor food intake are associated with prolonged hospital stay, frequent readmissions, and greater in-hospital mortality: results from the Nutrition Care Day Survey 2010. Clin Nutr 32, $737-745$

13. Vermeeren MA, Schols AM \& Wouters EF (1997) Effects of an acute exacerbation on nutritional and metabolic profile of patients with COPD. Eur Respir J 10, 2264-2269.

14. Sundwall P, Grönberg AM, Hulthén L, et al. (2005) Energy and nutrient intake in patients with chronic obstructive pulmonary disease hospitalized owing to an acute exacerbation. Scand J Nutr 49, 116-121. 
15. Vermeeren MA, Wouters EF, Geraerts-Keeris AJ, et al. (2004) Nutritional support in patients with chronic obstructive pulmonary disease during hospitalization for an acute exacerbation; a randomized controlled feasibility trial. Clin Nutr 23, 1184-1192.

16. Thorsdottir I \& Gunnarsdottir I (2002) Energy intake must be increased among recently hospitalized patients with chronic obstructive pulmonary disease to improve nutritional status. J Am Diet Assoc 102, 247-249.

17. Kondrup J (2001) Can food intake in hospitals be improved? Clin Nutr 20, 153-160.

18. Johansen N, Kondrup J, Plum LM, et al. (2004) Effect of nutritional support on clinical outcome in patients at nutritional risk. Clin Nutr 23, 539-550.

19. Yazdanpanah L, Shidfar F, Moosavi AJ, et al. (2010) Energy and protein intake and its relationship with pulmonary function in chronic obstructive pulmonary disease (COPD) patients. Acta Med Iran 48, 374-379.

20. Folstein MF, Folstein SE \& McHugh PR (1975) 'Mini-mental state'. A practical method for grading the cognitive state of patients for the clinician. J Psychiatr Res 12, 189-198.

21. Friðriksdóttir AJ \& Möller PH (2011) Clinical guidelines on patients nutrition. http://www.landspitali.is/lisalib/getfile. aspx?itemid=28242 (accessed May 2017).

22. Collins PF, Stratton RJ \& Elia M (2012) Nutritional support in chronic obstructive pulmonary disease: a systematic review and meta-analysis. Am J Clin Nutr 95, 1385-1395.

23. Bjornsdottir R, Oskarsdottir ES, Thordardottir FR, et al. (2013) Validation of a plate diagram sheet for estimation of energy and protein intake in hospitalized patients. Clin Nutr 32, 746-751.

24. Vilhjalmsdottir DO, Hinriksdottir HH, Pordardottir FR, et al. (2013) [Energy and protein intake of patients at the Department of Cardiothoracic surgery, Landspitali - the National University Hospital of Iceland]. Laeknabladid 99, 71-75.

25. Ingadottir AR, Beck AM, Baldwin C, et al. (2017) Two components of the new ESPEN diagnostic criteria for malnutrition are independent predictors of lung function in hospitalized patients with chronic obstructive pulmonary disease (COPD). Clin Nutr (epublication ahead of print version 8 June 2017).

26. Pauwels RA, Buist AS, Calverley PM, et al. (2001) Global strategy for the diagnosis, management, and prevention of chronic obstructive pulmonary disease. NHLBI/WHO Global Initiative for Chronic Obstructive Lung Disease (GOLD) Workshop summary. Am J Respir Crit Care Med 163, 1256-1276.

27. Celli B, Vestbo J, Jenkins CR, et al. (2011) Sex differences in mortality and clinical expressions of patients with chronic obstructive pulmonary disease. The TORCH experience. $\mathrm{Am}$ J Respir Crit Care Med 183, 317-322.

28. Gudmundsson G, Ulrik CS, Gislason T, et al. (2012) Long-term survival in patients hospitalized for chronic obstructive pulmonary disease: a prospective observational study in the Nordic countries. Int I Chron Obstruct Pulmon Dis 7, 571-576.

29. Schols AM (2013) Nutrition as a metabolic modulator in COPD. Chest 144, 1340-1345.

30. Schols AM, Soeters PB, Mostert R, et al. (1991) Energy balance in chronic obstructive pulmonary disease. Am Rev Respir Dis 143, 1248-1252.

31. Schols AM, Slangen J, Volovics L, et al. (1998) Weight loss is a reversible factor in the prognosis of chronic obstructive pulmonary disease. Am J Respir Crit Care Med 157, 1791-1797.

32. Hubbard GP, Elia M, Holdoway A, et al. (2012) A systematic review of compliance to oral nutritional supplements. Clin Nutr 31, 293-312.

33. Laudisio A, Costanzo L, Di Gioia C, et al. (2016) Dietary intake of elderly outpatients with chronic obstructive pulmonary disease. Arch Gerontol Geriatr 64, 75-81.
34. van de Bool C, Mattijssen-Verdonschot C, van Melick PP, et al. (2014) Quality of dietary intake in relation to body composition in patients with chronic obstructive pulmonary disease eligible for pulmonary rehabilitation. Eur J Clin Nutr 68, 159-165.

35. Weekes CE, Emery PW \& Elia M (2009) Dietary counselling and food fortification in stable COPD: a randomised trial. Thorax 64, 326-331.

36. Yilmaz D, Capan N, Canbakan S, et al. (2015) Dietary intake of patients with moderate to severe COPD in relation to fat-free mass index: a cross-sectional study. Nutr J 14, 35.

37. Khan NA, Daga MK, Ahmad I, et al. (2016) Evaluation of BODE index and its relationship with systemic inflammation mediated by proinflammatory biomarkers in patients with COPD. J Inflamm Res 9, 187-198.

38. Ehsan M, Khan R, Wakefield D, et al. (2013) A longitudinal study evaluating the effect of exacerbations on physical activity in patients with chronic obstructive pulmonary disease. Ann Am Thorac Soc 10, 559-564.

39. Pitta F, Troosters T, Probst VS, et al. (2006) Physical activity and hospitalization for exacerbation of COPD. Chest $\mathbf{1 2 9}$, 536-544.

40. Moore JA \& Angelillo VA (1988) Equations for the prediction of resting energy expenditure in chronic obstructive lung disease. Chest 94, 1260-1263.

41. Nordenson A, Gronberg AM, Hulthen L, et al. (2010) A validated disease specific prediction equation for resting metabolic rate in underweight patients with COPD. Int J Chron Obstruct Pulmon Dis 5, 271-276.

42. Creutzberg EC, Schols AM, Bothmer-Quaedvlieg FC, et al. (1998) Prevalence of an elevated resting energy expenditure in patients with chronic obstructive pulmonary disease in relation to body composition and lung function. Eur J Clin Nutr 52, 396-401.

43. Schols AM, Broekhuizen R, Weling-Scheepers CA, et al. (2005) Body composition and mortality in chronic obstructive pulmonary disease. Am J Clin Nutr 82, 53-59.

44. Almagro P, Calbo E, Ochoa de Echaguen A, et al. (2002) Mortality after hospitalization for COPD. Chest 121, 1441-1448.

45. Roberts MH, Clerisme-Beaty E, Kozma CM, et al. (2016) A retrospective analysis to identify predictors of COPD-related rehospitalization. BMC Pulm Med 16, 68.

46. Steer J, Norman E, Gibson GJ, et al. (2010) P117 Comparison of indices of nutritional status in prediction of in-hospital mortality and early readmission of patients with acute exacerbations of COPD. Thorax 65, A127-A127.

47. Ferreira IM, Brooks D, White J, et al. (2012) Nutritional supplementation for stable chronic obstructive pulmonary disease. Cochrane Database Syst Rev, issue 12, CD000998.

48. Collins PF, Elia M \& Stratton RJ (2013) Nutritional support and functional capacity in chronic obstructive pulmonary disease: a systematic review and meta-analysis. Respirology 18, 616-629.

49. Lee H, Kim S, Lim Y, et al. (2013) Nutritional status and disease severity in patients with chronic obstructive pulmonary disease (COPD). Arch Gerontol Geriatr 56, 518-523.

50. Luo Y, Zhou L, Li Y, et al. (2016) Fat-free mass index for evaluating the nutritional status and disease severity in COPD. Respir Care 61, 680-688.

51. Slinde F, Gronberg A, Engstrom CP, et al. (2005) Body composition by bioelectrical impedance predicts mortality in chronic obstructive pulmonary disease patients. Respir Med 99, 1004-1009.

52. Lainscak M, Gosker HR \& Schols AM (2013) Chronic obstructive pulmonary disease patient journey: hospitalizations as window of opportunity for extra-pulmonary intervention. Curr Opin Clin Nutr Metab Care 16, 278-283. 